\title{
The Praxeological Research Programme of Socio-Informatics - the Siegen School
}

\author{
Volker Wulf (D) 1,2, Anne Weibert ${ }^{1}$, Konstantin Aal (D) 1, Sarah Rüller (iD) 1, Markus Rohde ${ }^{1,2}$ \\ ${ }^{1}$ Information Systems and New Media, Faculty III, Siegen University, Kohlbettstr. 15, 57068 Siegen, Germany \\ 2 International Institute for Socio-Informatics (IISI), Stiftsgasse 25, 53111 Bonn, Germany \\ Corresponding author: Anne Weibert (anne.weibert@uni-siegen.de)
}

\begin{abstract}
This paper introduces the praxeologically grounded research programme on socio-informatics developed at the University of Siegen and the International Institute for Socio-Informatics in Germany. We outline our methodological framework of grounded design, guiding and binding together a variety of different engagements in practice which we call design case studies (DCS). While grounded design is applied to a broad variety of different areas, in this paper we deal specifically with our engagements in support of communities and political activists. To exemplify our approach, we present one DCS: It focuses on the participatory development of a computer club in the High Atlas as a facilitation infrastructure to support public community participation in the process of modernization and social transformation in the Maghreb. Insights into the project context, the objectives and methodology and the depiction of some of its first findings lays the ground for the discussion of socio-informatics research principles.
\end{abstract}

\section{Keywords}

Socio-informatics; Grounded design; Design case study; Information systems; Siegen school.

\footnotetext{
Citation: Wulf, V., Weibert, A., Aal, K., Rüller, S., \& Rohde, M. (2021). The Praxeological Research Programme of Socio-Informatics - the Siegen School. Acta Informatica Pragensia, 10(3), 333-348. https://doi.org/10.18267/j.aip.171 


\section{Introduction}

Research paradigms do not pop up in a vacuum. They usually develop over time and are institutionally embedded and framed by existing scientific discourses in reference communities. Our research programme on socio-informatics developed in the context of such discourses, in critical interaction with existing academic communities. It was shaped over time and inspired and influenced by existing literature, theoretical concepts and methodological frameworks.

The International Institute for Socio-Informatics (IISI) was founded in Bonn, Germany, in 2000 by a group of young researchers with highly interdisciplinary backgrounds, including computer scientists', psychologists', anthropologists', sociologists' and economists' competencies. The IISI became a crucial institutional base to start our exploration into making computer sciences more relevant for solving societal problems in the real world. We sought to understand the relationship between societal change, specifically on a micro level, and the design of meaningful information and communication technology (ICT) artifacts together with and in support of human actors. ICT artifacts are understood both as hardware and software applications that have been developed and implemented for practical use in a social context. To frame our research vision in concepts we still had to develop: we were interested in design-oriented investigations into the often-complex interaction between social practices and ICT artifacts implemented in their support; or more ambitiously framed, to explore how a turn to practice would spell out in the computing field.

Our group grew up in the normative realm of the German branch of the "Computers and Society" community. We chose the notion of socio-informatics to position our research perspective against the predominant management-oriented tradition of business informatics and, moreover, aimed to widen the narrow focus on business applications and underlying organizational processes towards a perspective that puts an emphasis on the social structures and practices in which these artifacts are embedded. In doing this, we benefitted greatly and contributed increasingly to the epistemological and methodological innovations emerging from the European Conference on Computer-Supported Cooperative Work (ECSCW) and Information Systems (IS).

Our understanding of socio-informatics as a new research discipline has been established in the form of a practice-based, inclusive and comprehensive research perspective. As Rohde and Wulf (2011) defined, "Socio-informatics should be seen as a transversal discipline of applied informatics, which analyses the design of information and communication technology (ICT artifacts) according to its sociotechnical double character. (...) Socio-informatics (is understood) as a sub-discipline of informatics that deals systematically with design of ICT artifacts with respect to their interaction with the social practices of their users. Here, the design quality of ICT artifacts is not only determined by formal, technological criteria, but additionally by the quality of their interdependency with the social systems in which they are applied and whose practices they structure" (Rohde and Wulf, 2011, p. 210, translation by the authors).

Socio-informatics, therefore, was not only meant to broaden the research focus from business processes to the wider field perspective of the development of a diverse set of social practices, but to re-define the epistemological stance of applied informatics and computer science as a field of practice-based design science in general. Thus, the new approach not only targeted the research subject (designing ICT artifacts for support of social practices), but the paradigmatic research logic and design practices of the scientific academic discipline as well. It was meant as a critical endeavour to reach a more inclusive informatics research perspective in computing, taking the social context of ICT design and research into account more explicitly and systematically.

The resulting interdisciplinary and strictly practice-oriented design research approach obviously requires - and necessarily develops - new methodological concepts, procedures and frameworks. Central among them is grounded design (Rohde et al., 2017), which is in line with IS research foundations with its core 
principle to see the quality of an IT design be "finally evaluated in its effectiveness in dealing with societally relevant problems" (Stevens et al., 2018, p. 29), and implements a design research view with its understanding of problem framing as ongoing effort in a design process (ibid.). It thus further diverges from the view Österle et al. (2011), who state the construction of artifacts should be "guided by the desire to yield a specific benefit and to satisfy certain objectives" (Österle et al., 2011, p. 9). In design case studies (Wulf et al., 2011; Wulf et al., 2015), the study of context, ICT artefact design for and with actors in the relevant field of practice, and observation of artifact design appropriation in practice over a longer period of time are understood and practised as "overlapping, interleaving and recursive" (Stevens et al., 2018, p. 31), thus aiming for what Winter (2008, p. 471) has described as the applicability to a set of problem situations. Further central concepts include integrated organization and technology development (Wulf and Rohde, 1995; Rohde and Wulf, 2018; Rohde, 2007), business ethnography (Stevens and Nett, 2009; Boden et al., 2011), end user development (Lieberman et al., 2006; Wulf et al., 2008), Praxlabs (Ogonowski et al., 2018), infrastructuring (Pipek and Wulf, 2009; Ludwig et al., 2018) and appropriation studies and infrastructures (Pipek, 2005; Stevens, 2009; Stevens et al., 2010; Stevens and Pipek, 2018).

These come together in socio-informatics as a research discipline

- forming a genuinely interdisciplinary sub-discipline of (applied) informatics or computer sciences,

- rooted in the discourse contexts of the ECSCW, the German Computers and Society communities as well as information systems (WI),

- understood as a design research discipline,

- with a strict practice-oriented and sociotechnical perspective on designing ICT artifacts for social practices,

- $\quad$ and a clear critical, self-reflective perspective on its own design practices and research activities.

Central is the systematic examination of ICT artefact design against the backdrop of their interaction with the social practices of their users. Such an ICT artifact-centred view is determined by the quality of their interaction with the social systems in which they are used and which they thereby restructure (Rohde and Wulf, 2011).

Smutny and Vehovar (2020) point to the diversity of the field, explaining how the variety of schools and understandings that have emerged has a grounding in linguistic meaning of the term's constituent parts "socio" or "social" and "informatics". There are other (partly similar, partly different) approaches to defining socio-informatics (e.g., Zweig et al., 2014). With a broader focus, Kling (2007) elaborated on the interdisciplinary character and institutional and cultural contextualization of the design, uses and consequences of information and communication technologies in what he calls "social informatics".

This paper focuses on the understanding of socio-informatics that has been established and developed over the last 20 years by the research group of the aforementioned International Institute for SocioInformatics (IISI) and is represented by scholars located at the University of Siegen, Germany. We illustrate the praxeological research programme of this "Siegen school" of socio-informatics by firstly introducing our core concepts of grounded design and design case studies (DCS). We then provide an overview of our research interest in socio-technical support for communities and political and civil society activists. After that, we exemplify this in a discussion of one DCS: the establishment of a computer club in a Moroccan village as a facilitation infrastructure to support public community participation in the process of modernization and social transformation in the Maghreb. Computer clubs are informal and open spaces which allow visitors to freely explore ICT in a safe and comfortable manner, often embedded in community projects. A more detailed definition and description of computer clubs can be found below. Insights into the project context, objectives and methodology and the depiction of some of its first findings lay the grounds for the discussion of socio-informatics research principles in the context of community support and political activism. 


\section{Grounded Design and Design Case Studies}

Our approach was also originally developed in direct response to the information system design discourse, especially addressing criticism of the influential paper by Hevner et al. (Hevner et al., 2004; Rohde et al., 2009). Our criticism was mainly directed against what we saw as a too positivistic perspective on IS design and we pleaded for a more constructivist-interpretivist perspective. In a detailed comparison of our grounded design approach with other design research approaches (for an overview in tabular form on the different approaches, see Rohde et al., 2017, p. 169), we show that the distinctive features of our approach are firstly its strict practice orientation and secondly that, in contrast to other perspectives, we place a central focus on appropriation research (Rohde et al., 2017). Our goal is not to design technical artifacts, but to support social practices; the quality of a technical solution and of any ICT design only becomes apparent in its impact in practice: how is it used/appropriated? How does it change existing practices?

Grounded design was introduced as a framework that elaborates on our (socio-technical) project approach when carrying out design case studies. It can be seen as contextualized by the tradition of design research in human-computer interaction (HCI) and information systems (IS), and aims to clarify its epistemological positioning (Rohde et al., 2017). Three types of activities are to be conducted while researching in the design case study framework: context studies, design studies and appropriation studies. We also define quality criteria when conducting design case studies. Finally, the question arises how to document design case studies, how to preserve and share the insights gained, and how to make the engagement in practice sustainable. This is a crucial issue for design research in general and different schools of design thinking have come up with different answers (Stevens et al., 2018).

Grounded design takes place in a very specific setting and interventions are based on very specifically designed artifacts. So, the question arises how to make these highly context-specific insights relevant for other cases of design and appropriation. Therefore, we argue for a detailed and broad documentation of the particularities of the different design case studies - beyond the mere publication of academic papers (Li et al., 2021). We argue that a comparative analysis of well documented design case studies allows comparative analysis and design-oriented concept building.

The grounded design paradigm suggests an orientation of the computing field towards understanding the relationship between specific settings and wider conceptions of the domain more clearly. Understanding, and designing for, problem issues in work contexts as well as public issues in a wider societal context requires procedures for establishing "boundary relevance". That is to ask, just how far the procedures we outline can take us in terms of scoping and limiting possibilities. Grounded design, we argue, provides a socio-technical approach for the solution of social issues in a context. It builds on a practice-based and constructivist (rather than positivist) paradigm, seeking to study emerging and evolving practices of use over longer periods of time after new IT artifacts have been designed and introduced. In that sense, grounded design suggests a praxeological turn in the field of computing.

Two driving forces nurture such an approach: (1) supporting evolving practices and evolving social challenges, and (2) new (basic) technological opportunities that may be employed to such ends. Grounded design explores new technological opportunities in the context of a certain domain of practice and its challenges to study the novel technology's fit with, and impact on, actual local practices over time.

By studying appropriation of an ICT artifact over time, grounded design is able to understand the transformation and fitting between a (newly) designed artifact, certain practices, and the context of use (cf. Stevens and Pipek, 2018). This leads to insights about practices of use that degrade, change or evolve in ways unexpected and surprising to the designer. Such insights about ICT appropriation and changing practices of use are crucial for the (re-)design of ICT artifacts. These are insights that often remain opaque with other approaches but fundamentally affect the design of future ICT artifacts. 
Assuming that the quality of ICT design could only be evaluated in social practice, we developed a research paradigm of a close coupling between empirical and design-oriented work. We explored the close coupling in a few of these design engagements (Hinrichs et al., 2005; Reichling and Wulf, 2009) and later on called the resulting framework design case studies (Wulf et al., 2011, 2015). A design case study documents the results of empirical studies, participatory design activities, and the implementation and roll-out of the resulting artifact into the field of investigation. So, empirical studies and design activities ideally take place in the same field of application. Empirical findings and the generated design solutions can directly refer to each other; the creative transition between them can be evaluated in practice.

The epistemological basis of socio-informatics research lies in the premise that all research results and technology adoption and use practices are deeply context-dependent. This points to a general challenge and tension regarding the use of empirical research results in design and their transferability and generalisation. Questions follow from this, such as in what form these results should be published so that other researchers can transfer them to further contexts. One orientation here is to present research results in the form of "sensitizing concepts" (Blumer, 1954).

One methodological aim of the design case study concept is the development of comparative criteria that help transfer results of individual design case studies and thus make them accessible to a broader scientific discourse. Today, the term sensitizing concept is often mentioned in relation to empirical studies that follow theory-generating procedures based on grounded theory (Corbin and Strauss, 1990). For some researchers, sensitizing concepts stand at the beginning of a qualitative empirical study in order to document the researcher's prior theoretical knowledge that s/he brings to the study. This prior knowledge to be revealed is used in the data collection phase as a heuristic-analytical framework to generate and structure the researcher's question ideas and perspectives (cf. Bowen, 2006).

Other authors use sensitizing concepts rather in the evaluation process of an empirical study for formulating the conceptual knowledge generated in the analysis. On the basis of an iterative, empirically based theory-generation process, these concepts function here as elastic intermediate steps of the knowledge process, which are further developed and refined in the ongoing analysis and consolidated with empirically justified hypotheses on the data material (Witzel, 2000). Sensitizing concepts thus serve - both at the beginning of an empirical study and in the ongoing analysis process - as a vehicle for documenting the changing research process between assumptions and concept formation in the researcher's mind and ongoing verification on the data material, thus guaranteeing the greatest possible practical relevance.

Sensitizing concepts thus form essential operationalisation stages in theory-generating procedures based on grounded theory. On the one hand, they symbolise a general critique - in Blumer's (1954) terms - of a sociological hypothetico-deductive approach based on the basic assumption of research methodology that empirical data collection and analysis must be based on operationalisation steps formulated in advance and must thus ultimately test existing hypotheses. On the other hand, they have a pragmatic significance for research, since they manifest the view of Corbin and Strauss (1990) that any research process is based on the researcher's presuppositions and prior knowledge and that a "naïve, inductivist position of 'sociological naturalism'” can never be realistically redeemed (cf. Witzel, 2000; Hoffmann-Riem, 1980). This perspective is directed against the demand of the researcher's principled openness towards empiricism as a "tabula rasa", i.e., completely excluding prior knowledge (Witzel, 2000; Kelle, 1995). According to Corbin and Strauss (1990), on the other hand, it should be a matter of actively incorporating prior knowledge as well as theoretical knowledge acquired in the course of the empirical study, e.g., through supplementary literature reviews, into the data basis in an ongoing process of data collection, theory generation and analysis.

The design case study approach thus proposes the description of research results as cross-cutting issues inspired by Blumer's sensitizing concepts (Wulf et al., 2015). These cross-cutting themes are differentiated 
into elements of the design process, namely as "analytical concepts" (for a better understanding of practice), as "design-oriented concepts" (for the thematization of typical design questions, challenges and principles that are relevant across the board) and as "methodological concepts" (which record overarching methodological aspects). Our presentation of a research project focusing on the establishment of a computer club in the High Atlas (Morocco) in Section 4 serves as one example of such a design case study.

\section{Research Domain: Support for Communities and Political Activists}

Over the last twenty years, our research has focused on a broad variety of societal issues, e.g., ICT support in traditional work settings, towards $\mathrm{CO}_{2}$ reduction in production and consumption, for an aging society with high quality of life, etc. In the following, we focus on one specific research domain, namely sociotechnical support for communities and political/civil society activists.

There is a common denominator to topics and activities in our work: approaching major global or societal issues through the perspective of particular settings in which these issues become manifest. To exemplify this for the research domain in focus here, this perspective has been the guiding principle in the case of the local, neighbourhood community context, where global topics such as migration and flight play out and have an immediate impact, and computer clubs have been conceptualized as a method for computational as well as cross-cultural learning and skill-building, providing a combined answer to the widening digital divide, as well as the increasing diversification of neighbourhood communities (Aal et al., 2014; Yerousis et al., 2015; Stevens et al., 2005; Weibert and Wulf, 2010; Weibert, Randall and Wulf, 2017; Weibert, 2020). Here also, a set of digital tools was designed helping with initial orientation, overview of language courses, information on cultural aspects, work, housing, and the structure of everyday life in general (Weibert et al., 2019; Krüger et al., 2021). Secondly, this is also the case where such a local setting becomes entangled in uprising, conflict and war. A series of works from the Siegen socioinformatics group has focused on the situation in Palestine (Aal et al., 2014; Yerousis et al., 2015; Wulf et al., 2013a), the Arab Spring (Aal et al., 2018; Rohde et al., 2016; Wulf et al., 2013b), the interrelation of social media use and political action following the Green Revolution in Iran (Wulf et al., in press), the Donbas conflict (Shklovski and Wulf, 2018), and the situation in Colombia following the Havana Peace Agreement between the government and the FARC guerrilla (de Castro Leál et al., 2019). Thirdly, this is the case where global environmental topics produce local challenges, as in Botswana, where the socio-informatics perspective provides a lens to approach the topic of land requirements of a fast-growing rural population versus the preservation of wild animals' habitats and develop a lion alert tracking application in a way that it went along with herders' needs and understandings as well as protection of the animals (Weise et al., 2019).

In all of the above works, the socio-informatics perspective brings to the fore an understanding of the imagination at work in technology appropriation. It helps to approach and conceptualize the learning and skill-building within, and to understand how these are channelled into local political or social and community action. Design here means socio-technical intervention - a holistic approach to technology and its current as well as envisioned role in a social context. Such a socio-informatics view can be seen as an approach that is driven by the researchers' curiosity to understand "the world" and their activist conviction to contribute to "a better world". The negotiations that happened as part of this DCS point to a need for researchers in the socio-informatics domain, and beyond, to ask what constitutes "better".

The socio-informatics perspective provides a standpoint from which to observe and engage with the rapid and profound changes affecting communities and individual actors within them. The political in this is the deliberate aim to come to an understanding of inherent power structures surrounding a topic, and to determine who has access and who does not, who gets to speak and who does not, and how and why all this feeds into action or inaction. There is close interdependency of technological development and social transformation, and the (participatory) action research paradigm (e.g., Lewin, 1946; Whyte et al., 1991; 
Maguire, 1996) that speaks from some of our research considers technological intervention as a lens that fosters an understanding of evolving practices around the respective topic.

\section{Example DCS: Establishing a Computer Club in the High Atlas}

As part of Collaborative Research Centre 1187 "Media of Cooperation" at the University of Siegen (funded by the DFG, the German Research Foundation), members of the Siegen socio-informatics group research ways in which digitization is shaping life practices and political views and actions of the public in rural parts of Morocco. Since 2016, the team works ethnographically in a remote valley in the High Atlas Mountains in Central Morocco, also exploring opportunities that computer clubs offer in these contexts (Aal et al., 2018; Rüller et al., 2021; Rüller et al., 2022). Together with colleagues from Media Anthropology at the University of Cologne, they focus on the challenges of co-establishing such an intervention in a rural/mountainous region that is already undergoing a process of continuous development and profound transformation. In the following, we briefly present this project and some of our main insights as an example of a socio-informatics design case study.

\subsection{Research setting}

This research is situated in rural parts of Morocco, specifically a valley in the High Atlas. Around 10,000 residents live in the valley in six smaller villages, of which the oldest one is said to have a history dating back to the end of the $13^{\text {th }}$ century.

Agriculture and pastoralism have the major share in the valley's economy, including transhumance, i.e., seasonal moving of livestock to pastures on higher grounds surrounding the valley. Furthermore, men have employments in the local administration, in construction or tourism. The big cities also have an impact on work life in the valley and a significant share of men has left the valley to find employment there. Work is often gendered, with women being responsible for the housework and the house; in agriculture, specific tasks (such as ploughing) being performed by men only, while others (such as pulling up weeds) are the duty of women.

Life in the valley is also shaped in stark contrast to the urban areas in Morocco. Basic infrastructures or medical care as well as access to job opportunities and education are in great part lacking in the very remote rural areas. The residents living in those areas primarily belong to the ethnic group of Imazighen (Berbers). In 2018, a total of 6,884,539 Moroccans above the age of 15 were illiterate, of which 2,143,819 were male and 4,740,720 were female ${ }^{1}$. Official statistics for Imazighen are not available, but it can be concluded from informal data for the valley that the majority of female Imazighen above the age of 18 are illiterate (Dodson et al., 2013; Slawson, 2016). In contrast to the rural male Amazigh population, most of the women also mainly speak Tamazight and only rudimentary or no Moroccan Arabic (Hoffman, 2008).

The situation is gradually changing, with important infrastructural improvements and developments being conducted in the region since the mid-2000s. Access to running water and electricity is now provided for households in the main villages, and the major road to and from the valley has been paved. Furthermore, a health centre with two nurses and three ambulance cars has been installed for the valley, and a new school has been built. A set of telephone poles now provide LTE network coverage for the entire valley.

Increasing engagement of various mostly foreign NGOs in the valley is concerned with agricultural, touristic and cultural heritage topics such as restoration of cultural heritage sights and further improvement of living conditions.

\footnotetext{
${ }^{1}$ See, http://uis.unesco.org/country/MA
} 


\subsection{The project: objectives and methodology}

The grounded, situated socio-informatics perspective is apparent in the main methodological framing of this DCS based on a participatory action research approach (PAR) (Kemmis and McTaggart, 2005) - with an extended scope on meta-research. For a total of 18 weeks, two of the authors of this paper were present on the field site in Morocco. In addition to that, one of the members of the project team, an anthropologist, lived and conducted media ethnographic fieldwork in the valley for about a year. In parallel, research into the concept of computer clubs was conducted in a mid-sized city in Germany (see, e.g., Weibert, Oertel Ribeiro and Wulf, 2017a; Weibert et al., 2017c) with a large Moroccan community who have mostly immigrated from the same rural area where our DCS is situated.

The intervention in the High Atlas was initially planned to span a period of four years, due to the nature of the project funding. These four years were intended to include the exploration, setting up of the enabling infrastructure, professionalization of the coordinators and tutors, and a first evaluation of the entire intervention, as well as examination of the appropriation processes. After this first phase, we wanted to look at ways of continuing the project and, thus, extending the cooperatively created structures.

Being part of the intervention in Morocco, the researchers follow a grounded design approach (Wulf et al., 2018) to the local situation, its infrastructure, challenges and the various actors present. This is captured by means of largely observational, qualitative methods, and completing the picture gained with informal and narrative interviews, so that the researchers can reconstruct the social practices observed before and during the design and appropriation of ICT interventions as design case studies. For the researchers, this involved understanding the local situation, finding partners and eventually establishing the computer club. Each of the stays in the valley further contributed to a refined understanding of the local situation. The long-term involvement, extended stays involving participant observation, narrative interviews and also learning to communicate in Moroccan Arabic and Tamazight, the native language of the Imazighen, enabled an understanding of the significance and usage of media technology, and to guide along and follow the implementation and appropriation of the socio-technical intervention, the computer club. The researchers documented this with field notes that were written every evening. There the experiences and impressions of the day were described in relation to various topics of relevance, e.g., political power distribution, gender aspects and ICT usage.

Right from the start it was very important to establish a close contact with a local NGO focused on improvement of infrastructures in the valley and on hosting of cultural activities, empowerment of women and educational support of children. In its work with the community over the course of the past 13 years, this NGO had established a basis of trust with the local residents, which was further reinforced by the fact that its founder as well as all members originated from this same valley. Thus, they owned crucial knowledge about local social relations, local ways of proceeding and local concerns, all relevant to a sustainable way to set up our socio-technical intervention.

\subsubsection{Field visits}

A total of seven field visits form the basis on which the intervention was successfully started and carried out. This started with a first stay in the valley in late 2015, where one of the researchers stayed in one of the guesthouses and established initial contact with the partners on the ground. First contacts had been made beforehand through the founder of an American NGO working in the area. During a second stay in March 2016, contact was made with local schools and NGOs to talk about potential cooperation. This stay ended with the prospect of a further visit of the researchers later in the same year that would then be connected with a longer stay. This was put into practice in August 2016, when one researcher of the team stayed in the village for six weeks to proceed with the planning of the cooperation for which a contract could be signed at the end of the stay. Furthermore, one of the researchers stayed in Morocco for a language course. Thus, a basis of trust was established on which expectations could be discussed and 
solutions found in a productive and transparent manner. Subsequently, the anthropologist stayed in the village for almost twelve months until October 2017.

The opening of the computer club took place in April 2017 and was in relation to another field visit of several of the researchers who also brought hardware and software to the valley and got engaged in initial workshops for tutors of the new computer club, and who also participated in its first sessions.

In June 2017 another field visit took place, where new technology was brought to the space and new training for tutors was conducted. A visit of the Moroccans to Germany was cancelled because of problems with the visa process. Another visit to the valley took place in July 2018, and the German researchers were able to observe how the computer club had come into life and was appropriated by the local residents. The tutors had continued to work with the technology and conducted new computer club projects with the participants.

The parallel work with the computer club in Germany provided learning opportunities about project activities, and experiences with paper-crafts and electronics, as well as digital storytelling as a creative expression of identity, migration and/or aspects of everyday life were explored and shared to learn from mutually. The Moroccan project partners were able to follow the invitation of the German researchers and come to visit them and the computer clubs in Germany in March 2019 at last. That way, a mutual understanding of what a computer club could mean in terms of projects and participation structure was fostered. The German research team hoped to further strengthen a trustful and open relationship for the ongoing collaboration, and to ensure that things worked out well for everyone involved - researchers as well as local partners. It takes time, effort and care to foster and support a mutual understanding with an eye for cultural differences, and with regard to the methodological approach.

In February 2020, the last visit of three of the project members took place to conduct new workshops with the participants and to see how the space, its use and the general dynamics had changed since the last trip. New courses had been set up by the local partners, especially for illiterate women. This was also a result of the discussions during the visit of the Moroccan NGO to Germany.

\subsubsection{Data analysis}

We applied principles of qualitative content analysis (see, e.g., Schreier, 2014) to analyse our findings, notes and documentation of the unfolding intervention. This entailed controlled analysis of interviews and texts within their respective communicative context. Analysis took place within the research team as well as with colleagues not immersed in the field to avoid individual researcher bias.

\subsection{Empirical findings}

Understanding the local situation, setting the framework for cooperation, workshops and training are the main themes that resulted from our qualitative content analysis in this DCS. They are briefly described in the following.

Understanding the local situation. This has meant firstly the recognition of existing local educational perspectives, structures and skills. The computer club was included in the local partner NGO's wellknown and proven concept of tutoring, which is practised under the supervision of teachers and trained staff. A newly recruited employee was hired by the NGO specifically for the computer club. That way a structure was set up comparable to the setup of computer clubs in Germany, with an accompanying tutor as well as a teacher from a hosting school involved (Schubert et al., 2011). Such recognition of local stakeholders and power relations in the form of the inclusion of local community members in a "managing" position confirms related works of Aker et al. (2012) and Zegura and Grinter (2013) and puts a socio-informatics perspective into practice aiming to enable early identification with the project to sustain effects. 
Setting the framework for cooperation. It turned out that it is supportive to the acceptance of the intervention when existing structures are involved and utilized as far as possible, and partners are involved right from the start so that a mutual understanding and trust can be developed and sustained. In the case of the computer club, this meant that its opening hours were adapted to the times of existing courses and in response to school hours and the calendar of tourist activities relevant to the valley.

Importantly, the cooperation meant to negotiate the expectations of all stakeholders (locals, the partner NGO, but also people in power such as the traditional form of political organization, the tribe and the sheikh), and to carefully balance project goals and local perspectives (for a reflection of this along similar lines, see Zegura and Grinter (2013). For the research team, this meant to step back from their own knowledge and experience with setup and structure of computer clubs (see, e.g., Aal et al., 2014, 2015; Yerousis et al., 2015), and to be attentive to the local notions of such a space, and to the expectations of what it should mean for the valley. Irani et al. (2010) highlight the importance of evading forms of paternalism and being careful to avoid reproducing (colonial) power asymmetries.

Workshops and training. Findings from our case highlight some topics that were central to the learning and training that a computer club demands and provides. Firstly, the possibility to communicate and to talk and plan and develop ideas and the overall concept jointly in person as part of the field travels were key and could not be substituted digitally. Communication without a common language and direct channel bears great difficulties. For the case of the computer club in the High Atlas valley, this meant that the research team did not know exactly for a longer period of time whether any activities were taking place at the computer club, even though a local "manager" was employed. Two perspectives had to come together at this point. For one, in the view of the local NGO, it was the duty of the researchers to provide the local "managers"/tutors with training and precise instruction on how to fill the computer club with life. On the other hand, the researchers' concept and experience was such that there should be freedom to figure out topics of interest and needed skills locally, and tutors should be encouraged to train themselves (Ahmed et al., 2015; Ndaiga and Salim, 2015). As a compromise, a training with basic tutoring skills was provided, which was conceptualized in a way that it subsequently enabled independent learning of new content via the internet.

Secondly, notions of appropriate ways to conceptualize workshops and trainings varied. Locally, frontal teaching and little variety of learning modes initially prevailed. Consequently, the computer club initially did not include "maker-oriented" ideas and did not seek to bring together tutors and children as a community of learners that the researchers had envisioned. Low ICT literacy amplified this issue at first, and the project had to adjust its internal schedule to allow more time to develop a shared understanding of learning and skill-building.

A shared understanding had to be developed of what the audience for the computer club and its activities would be. The researchers brought the idea to take a broad approach and reach out to as many interested people as possible, inviting all to join the computer club for work on their individual project ideas - thus creating an atmosphere of mutual learning by doing. This stood in initial contrast to gendered views on societal roles, and the project had to adapt to the view that women would not attend mixed computer club sessions that were run by a male tutor. When the local NGO had established their tutoring programme for school children, they first geared the computer club activities towards these children and integrated the computer club as one component into their existing tutoring programme - with the vision to then expand this in the future.

Lastly, the question of internet access was a space where learning and skill-building perspectives needed to be negotiated and common ground be found at the start of the intervention. From the perspective of the research team, such internet access was a basic requirement for the success of all subsequent activity. But from the perspective of the local partners, internet access was associated with problems such as distraction from learning and the provision of potentially harmful content. Accordingly, they argued for 
access only in the presence of tutoring staff in the computer club, in order to have control over online activity that children were able to pursue during club time. At the same time, the local partners recognized the ubiquity of smartphones in the Moroccan society ${ }^{2}$. Here, ongoing project activity in the computer club, where digital storytelling and theatre play are explored as socio-technical means to support the preservation of local history and identity, can provide a way to experience the digital as a supportive mode for creative expression.

\section{Discussion and Conclusions}

Our grounded design perspective implies working on the artefact as well as working with the artefact in the social context of use. Following this principle, our socio-informatics research approaches design as socio-technical intervention. Developing answers to the umbrella question what could and should be done for this world to make it a place that is equally liveable for all has been at the core of an abundance of research across disciplines, intersecting policy and public discourse and inherent social as well as political and economic action (see, e.g., Castells, 2014; Eagle and Greene, 2014; Komives and Wagner, 2012; McGonigal, 2011; Trahair, 2013). Socio-informatics takes a strength from its grounded perspective, seeking to develop answers and socio-technical interventions that are rooted in human practice. As an "informatics with a human face", it seeks to shed light on actors, neighbourhoods and regions such as the remote valley in the High Atlas from a political point of view and driven by the impulse to understand. Such research seeks to hear and understand the voices of the citizens, practitioners and activists whom it meets and engages with (for further and related discourse on this striving for eye-level communication, see, e.g., Wilson et al., 2020; McNaney et al., 2018; Alper, 2017). Our DCS from the High Atlas in Morocco shows how this support of social practices can mean a number of things with regard to both ICT design and support of ICT appropriation in the form of innovative socio-technical intervention. The newly established computer club in the High Atlas can be understood as an enabling infrastructure - a space that, by introducing, configuring and combining ICT, enables the development of new social practices and broadening of public (media) participation.

The research domain of community support and political activism can involve taking the empirical work of socio-informatics as a means to bring hidden phenomena and problems to public perception and attention, thus adding voice to domains otherwise influenced by journalism. To hear and to understand the voices of the citizens, practitioners and activists can also bring about detours and creative modes of expression, as has happened in the case of the computer club in Morocco, as well as computer clubs in Palestine and Germany, which have repeatedly engaged in jointly conducted activities that spanned neighbourhoods and topics and created mutual awareness (Weibert et al., 2017b), appreciation and social capital (Weibert, Aal, Ribeiro and Wulf, 2017a). The sometimes conflicting views along the lines of stakeholder involvement, participation structures, audience, gender roles, learning and digitization have - in the case of our example - brought forward the need for constant negotiation, trust building and eyelevel communication. Weibert et al. (2021) discuss how such intervention sees innovation as a combination of the profound understanding of (hidden) practices, early and continuous involvement of local stakeholder values and perspectives and networking thereof in a grassroots manner, to sustain and scale effects.

It is the role of information and communication technology and the theme of digitization that connects activism to academic discourses and creates visibility in the form of publications in those international venues where socio-informatics contributions are appreciated. The view across socio-informatics works concerned with community and political activism brings to the fore the strength that lies in the bottom-

${ }^{2}$ See, National Telecommunications Regulations Agency (ANRT): https://www.anrt.ma/en/lagence/actualites/smart 
up approach that socio-informatics works with. This is what enables the profound and grounded understanding of an issue and its development. This forms a necessary basis for the subsequent balancing of risks and opportunities involved. It forms a basis on which trust can grow which then enables cocreation and collaboration in design and socio-technical intervention. It is related to specific challenges emerging from the respective topics but also based on personalities and specific experiences and agendas, and closely linked to and dependent on local partners with whom the researchers jointly try to uncover the hidden and facilitate change through participatory design. For all such activities, the researchers depend on local actors - be it as informants, facilitators or co-designers.

Tackling delicate and (politically) sensitive issues, such research needs to be developed in close collaboration with local actors with a congruent (political) agenda with whom a relation of trust has been established over time (cf. Rohde, 2013). Looking at sensitive, conflict-loaded and often hidden aspects of communities and societies requires specific skills in the researchers. Being in a zone of conflict (sometimes war), talking to political activists or guerrilla fighters or publishing about sensitive or censored issues can be dangerous for the researchers and more so for their local informants. Following an activist research agenda can be even more of a security challenge and activities need a balance between taking risks and missing opportunities, and high or unreasonable risks should not be taken. However, such an assessment often cannot be made in advance and in the abstract. Instead, it needs to be carried out in a process of constant self-reflection and joint risk assessment and learning. This process also involves thorough research into the topic and site before entering, and it includes mutual learning within the research team, where junior researchers can learn from senior colleagues. The need for constant reflection extends from field work towards publication. Publishing results can be equally dangerous - specifically for the informants, who need to be protected. Here again, the danger for informants is often difficult to judge in some cases they even prefer to be explicitly named in academic publications as a strategy that may serve towards their protection.

It takes time to enculturate in such research practice, and it frequently goes against the grain of what is common, project-fuelled practice in the academic field: to see and follow topics where there is not yet a funding line for them, to learn how to travel in a socially and culturally attentive and sensitive manner, to work on building sustainable relationships with informants and local cooperating partners, to keep activities going and let change emerge from this (in a partly remote manner), to see and accept change that does not happen as part of the answer, and to distil scientifically publishable themes that are grounded in such engagement with local people and communities.

\section{Additional Information and Declarations}

Acknowledgements: We are deeply grateful to our participants, who shared experiences with us. Thank you for your trust. A special thanks goes also to all collaborators who provided valuable feedback. Thank you also to the special issue editors and anonymous reviewers whose thoughtful and kind remarks have strongly improved this manuscript.

Funding: The empirical work presented here was funded by the German Research Foundation (DFG) in the context of the Collaborative Research Centre Media of Cooperation (project no. 262513311 - SFB 1187). Gefördert durch die Deutsche Forschungsgemeinschaft (DFG) Projektnummer 262513311 - SFB 1187.

Conflict of Interests: The authors declare no conflict of interest.

Author Contributions: V.W.: Conceptualization, Investigation, Methodology, Writing original draft, Writing - review \& editing. A.W.: Methodology, Writing - original draft, Writing - review \& editing. K.A.: Investigation, Methodology, Writing - original draft, Writing - review \& editing. S.R.: Investigation, Methodology, Writing - original draft, Writing 
- review \& editing. M.R.: Conceptualization, Investigation, Methodology, Writing - original draft, Writing - review \& editing.

\section{References}

Aal, K., Schorch, M., Elkilani, E. B. H., \& Wulf, V. (2018). Facebook and the mass media in Tunisia. Media in Action. Interdisciplinary Journal on Cooperative Media, (1), 135-168. https://doi.org/10.25819/ubsi/8269

Aal, K., Rüller, S., Holdermann, S., Tolmie, P., Rohde, M., Zillinger, M., \& Wulf, V. (2018). Challenges of an Educational ICT Intervention: The Establishment of a MediaSpace in the High Atlas. International Reports on Socio-Informatics, 15(2), 120.

Aal, K., von Rekowski, T., Yerousis, G., Wulf, V., \& Weibert, A. (2015). Bridging (Gender-Related) Barriers: A comparative study of intercultural computer clubs. In Proceedings of the Third Conference on Gender/T (pp. 17-23). ACM. https://doi.org/10.1145/2807565.2807708

Aal, K., Yerousis, G., Schubert, K., Hornung, D., Stickel, O., \& Wulf, V. (2014). Come_in@ palestine: adapting a german computer club concept to a palestinian refugee camp. In Proceedings of the 5th ACM international conference on Collaboration across boundaries: culture, distance \& technology (pp. 111-120). ACM. https://doi.org/10.1145/2631488.2631498

Ahmed, N., Haque, A. M., \& Doyle, L. (2015). Entering the dream world of computers. In Proceedings of the Seventh International Conference on Information and Communication Technologies and Development (pp. 1-4). ACM. https://doi.org/10.1145/2737856.2737860

Aker, J. C., Ksoll, C., \& Lybbert, T. J. (2012). Can Mobile Phones Improve Learning? Evidence from a Field Experiment in Niger. American Economic Journal: Applied Economics, 4(4), 94-120. https://doi.org/10.1257/app.4.4.94

Alper, M. (2017). Giving Voice: Mobile communication, disability, and inequality. MIT Press

Blumer, H. (1954). Sensitizing concepts. American Sociological Association.

Boden, A., Müller, C., \& Nett, B. (2011). Conducting a Business Ethnography in Global Software Development projects of small German enterprises. Information and Software Technology, 53(9), 1012-1021. https://doi.org/10.1016/j.infsof.2011.01.009

Bowen, G. A. (2006). Grounded Theory and Sensitizing Concepts. International Journal of Qualitative Methods, 5(3), 12-23. https://doi.org/10.1177/160940690600500304

Castells, M. (2014). Technopoles of the world: The making of 21st century industrial complexes. Routledge.

de Castro Leal, D., Krüger, M., Misaki, K., Randall, D., \& Wulf, V. (2019). Guerilla Warfare and the Use of New (and Some Old) Technology: Lessons from FARC's Armed Struggle in Colombia. In Proceedings of the $2019 \mathrm{CHI}$ Conference on Human Factors in Computing Systems (pp. 1-12). ACM. https://doi.org/10.1145/3290605.3300810

Corbin, J. M., \& Strauss, A. (1990). Grounded theory research: Procedures, canons, and evaluative criteria. Qualitative Sociology, 13(1), 3-21. https://doi.org/10.1007/bf00988593

Dodson L. L., Sterling S. R., \& Bennett J. K. (2013). Minding the gaps: cultural, technical and genderbased barriers to mobile use in oral-language Berber communities in Morocco. In Proceedings of the Sixth International Conference on Information and Communication Technologies and Development (pp 79-88). ACM. https://doi.org/10.1145/2516604.2516626

Eagle, N. \& Greene, K. (2014). Reality mining: Using big data to engineer a better world. MIT Press.

Hevner, A., March, S., Park, J., \& Ram, S. (2004). Design Science in Information Systems Research. MIS Quarterly, 28(1), 75-105. https://doi.org/10.2307/25148625

Hinrichs, J., Pipek, V., \& Wulf, V. (2005). Context Grabbing: Assigning Metadata in Large Document Collections. In Proceedings of the Ninth European Conference on Computer Supported Cooperative Work (pp. 367-386). Springer. https://doi.org/10.1007/1-4020-4023-7 19

Hoffman K. E. (2008). We share walls: Language, land, and gender in Berber Morocco. John Wiley \& Sons.

Irani, L., Vertesi, J., Dourish, P., Philip, K., \& Grinter, R. E. (2010). Postcolonial computing: a lens on design and development. In Proceedings of the SIGCHI conference on human factors in computing systems (pp. 1311-1320). ACM. https://doi.org/10.1145/1753326.1753522

Kelle, U. (1995). Die Bedeutung theoretischen Vorwissens in der Methodologie der Grounded Theory. In Wahre Geschichten? Zur Theorie und Praxis qualitativer Interviews (pp. 23-47). Nomos.

Kemmis S., \& McTaggart R. (2005). Participatory Action Research: Communicative Action and the Public Sphere. Sage.

Kling, R. (2007). What Is Social Informatics and Why Does It Matter? The Information Society, 23(4), $205-220$. https://doi.org/10.1080/01972240701441556

Komives, S.R., \& Wagner, W. (2012). Leadership for a better world: Understanding the social change model of leadership development. John Wiley \& Sons.

Krüger, M., Weibert, A., Leal, D. D. C., Randall, D., \& Wulf, V. (2021). It Takes More Than One Hand to Clap: On the Role of 'Care' in Maintaining Design Results. In Proceedings of the 2021 CHI Conference on Human Factors in Computing Systems (pp. 1-14). ACM. https://doi.org/10.1145/3411764.3445389 
Lewin, K. (1946). Action Research and Minority Problems. Journal of Social Issues, 2(4), 34-46. https://doi.org/10.1111/j.15404560.1946.tb02295.x

Li, Q., Tolmie, P., Weibert, A., Schorch, M., Müller, C., \& Wulf, V. (2021). E-Portfolio: value tensions encountered in documenting design case studies. Ethics and Information Technology, 23(1), 89-93. https://doi.org/10.1007/s10676-02009533-3

Lieberman, H., Paternò, F., Klann, M., \& Wulf, V. (2006). End-user development: An emerging paradigm. In End user development (pp. 1-8). Springer. https://doi.org/10.1007/1-4020-5386-X 1

Ludwig, T., Dax, J., Pipek, V., \& Wulf, V. (2017). A practice-oriented paradigm for end-user development. In New perspectives in end-user development (pp. 23-41). Springer. https://doi.org/10.1007/978-3-319-60291-2 2

Ludwig, T., Pipek, V., \& Tolmie, P. (2018). Designing for Collaborative Infrastructuring. Proceedings of the ACM on HumanComputer Interaction, 2(CSCW), 1-29. https://doi.org/10.1145/3274382

Maguire, P. (1996). Considering More Feminist Participatory Research: What's Congruency Got to Do With It? Qualitative Inquiry, 2(1), 106-118. https://doi.org/10.1177/107780049600200115

McGonigal, J. (2011). Reality is broken: Why games make us better and how they can change the world. Penguin.

McNaney, R., Wilson, C., Wallace, J., Brereton, M., Roper, A., Wilson, S., \& Sturdee, M. (2018). Giving a voice through design: adapting design methods to enhance the participation of people with communication difficulties. In Proceedings of the 15th Participatory Design Conference: Short Papers, Situated Actions, Workshops and Tutorial - Volume 2 (pp. 1-3). ACM. https://doi.org/10.1145/3210604.3210648

Ndaiga, W., \& Salim, A. (2015). Kids hacker camps in Kenya: hardware hacking effectiveness in skills transfer. In Proceedings of the Seventh International Conference on Information and Communication Technologies and Development (pp. 1-4). ACM. https://doi.org/10.1145/2737856.2737873

Österle, H., Becker, J., Frank, U., Hess, T., Karagiannis, D., Krcmar, H., Loos, P., Mertens, P., Oberweis, A., \& Sinz, E. J. (2011). Memorandum on design-oriented information systems research. European Journal of Information Systems, 20(1), 7-10. https://doi.org/10.1057/ejis.2010.55

Ogonowski, C., Jakobi, T., Müller, C., \& Hess, J. (2018). Praxlabs: A Sustainable Framework for User-Centered Information and Communication Technology Development-Cultivating Research Experiences from Living Labs in the Home. In Socio-Informatics. Oxford University Press. https://doi.org/10.1093/oso/9780198733249.003.0011

Pipek, V. A. (2005). From tailoring to appropriation support: Negotiating groupware usage. http://jultika.oulu.fi/files/isbn9514276302.pdf

Pipek, V., \& Wulf, V. (2009). Infrastructuring: Toward an Integrated Perspective on the Design and Use of Information Technology. Journal of the Association for Information Systems, 10(5), 447-473. https://doi.org/10.17705/1jais.00195

Reichling, T., \& Wulf, V. (2009). Expert recommender systems in practice: evaluating semi-automatic profile generation. In Proceedings of the SIGCHI Conference on Human Factors in Computing Systems (pp. 59-68). ACM. https://doi.org/10.1145/1518701.1518712

Rohde, M., Stevens, G., Brödner, P., \& Wulf, V. (2009). Towards a paradigmatic shift in IS: designing for social practice. In Proceedings of the 4th International Conference on Design Science Research in Information Systems and Technology (pp. 1-11). ACM. https://doi.org/10.1145/1555619.1555639

Rohde, M., \& Wulf, V. (2017). Integrated Organization and Technology Development (OTD): a critical evaluation. In Socio-Informatics (pp. 279-302). Oxford University Press. https://doi.org/10.1093/oso/9780198733249.003.0009

Rohde, M., Brödner, P., Stevens, G., Betz, M., \& Wulf, V. (2017). Grounded Design - a praxeological IS research perspective. Journal of Information Technology, 32(2), 163-179. https://doi.org/10.1057/jit.2016.5

Rohde, M., Aal, K., Misaki, K., Randall, D., Weibert, A., \& Wulf, V. (2016). Out of Syria: Mobile Media in Use at the Time of Civil War. International Journal of Human-Computer Interaction, 32(7), 515-531. https://doi.org/10.1080/10447318.2016.1177300

Rohde, M., \& Wulf, V. (2011). Sozio-Informatik. Informatik-Spektrum, 34(2), 210-213.

Rohde, M. (2007). Integrated organization and technology development (OTD) and the impact of socio-cultural concepts: a CSCW perspective. Doctoral dissertation. Roskilde University.

Rüller, S., Aal, K., Holdermann, S., Tolmie, P., Hartmann, A., Rohde, M., Zillinger, M., \& Wulf, V. (2021, in press). "Technology is Everywhere, we have the Opportunity to Learn it in the Valley": The Appropriation of a Socio-Technical Enabling Infrastructure in the Moroccan High Atlas. Computer Supported Cooperative Work. https://doi.org/10.1007/s10606-021-09401-8

Rüller, S., Aal, K., Tolmie, P., Hartmann, A., Rohde, M., \& Wulf, V. (2022). Speculative Design as a Collaborative Practice: Ameliorating the Consequences of Illiteracy through Digital Touch. ACM Transactions on Computer-Human Interaction, 29(3), 1-58. https://doi.org/10.1145/3487917

Schreier, M. (2014). Ways of doing qualitative content analysis: disentangling terms and terminologies. Forum Qualitative Sozialforschung / Forum: Qualitative Social Research, 15(1), Article no. 18. https://doi.org/10.17169/FQS-15.1.2043

Schubert, K., Weibert, A., \& Wulf, V. (2011). Locating computer clubs in multicultural neighborhoods: How collaborative project work fosters integration processes. International Journal of Human-Computer Studies, 69(10), 669-678. https://doi.org/10.1016/j.ijhcs.2010.12.007 
Shklovski, I., \& Wulf, V. (2018). The use of private mobile phones at war: Accounts from the donbas conflict. In Proceedings of the $2018 \mathrm{CHI}$ Conference on Human Factors in Computing Systems (pp. 1-13). ACM. https://doi.org/10.1145/3173574.3173960

Slawson N. (2016). In Morocco's Atlas mountains, Berber girls find the way out of rural poverty: an education. The Guardian. https://www.theguardian.com/world/2016/jun/18/girls-poverty-school-university-morocco-africa

Smutny, Z., \& Vehovar, V. (2020). Social Informatics Research: Schools of Thought, Methodological Basis, and Thematic Conceptualization. Journal of the Association for Information Science and Technology, 71(5), 529-539. https://doi.org/10.1002/asi.24280

Stevens, G. (2009). Understanding and Designing Appropriation Infrastructures: Artifacts as boundary objects in the continuous software development. Doctoral dissertation. University of Siegen.

Stevens, G., Rohde, M., Korn, M., Wulf, V., Pipek, V., Randall, D., \& Schmidt, K. (2018). Grounded design. A research paradigm in practice-based computing. In Socio-Informatics (pp. 23-46). Oxford University Press. https://doi.org/10.1093/oso/9780198733249.003.0002

Stevens, G., \& Pipek, V. (2018). Making use: understanding, studying, and supporting appropriation. In Socio-Informatics (pp. 139-176). Oxford University Press. https://doi.org/10.1093/oso/9780198733249.003.0005

Stevens, G., \& Nett, B. (2009). Business Ethnography as a research method to support evolutionary design. NavigationenZeitschrift für Medien-und Kulturwissenschaften, 9(2), 119-136.

Stevens, G., Pipek, V., \& Wulf, V. (2010). Appropriation Infrastructure: Mediating appropriation and production work. Journal of Organizational and End User Computing, 22(2), 58-81. https://doi.org/10.4018/joeuc.2010040104

Stevens, G., Pipek, V., \& Wulf, V. (2009). Appropriation infrastructure: Supporting the design of usages. In International Symposium on End User Development (pp. 50-69). Springer. https://doi.org/10.1007/978-3-642-00427-8 4

Stevens, G., Veith, M., \& Wulf, V. (2005). Bridging among ethnic communities by cross-cultural communities of practice. In Communities and Technologies 2005 (pp. 377-396). Springer. https://doi.org/10.1007/1-4020-3591-8 20

Trahair, R. C. (2013). Utopias and Utopians: An Historical Dictionary of Attempts to Make the World a Better Place and Those Who Were Involved. Routledge

Weibert, A., Aal, K., Rohde, M., \& Wulf, V. (2021). Scaling local experiences to global challenges: insights from grounded design and value sensitive design. Ethics and Information Technology, 23(1), 33-37. https://doi.org/10.1007/s10676-018$\underline{9470-8}$

Weibert, A., Krüger, M., Aal, K., Salehee, S. S., Khatib, R., Randall, D., \& Wulf, V. (2019). Finding Language Classes. Proceedings of the ACM on Human-Computer Interaction, 3(CSCW), 1-23. https://doi.org/10.1145/3359218

Weibert, A., Aal, K., Oertel Ribeiro, N., \& Wulf, V. (2017a). "This is My Story..." Storytelling with Tangible Artifacts among Migrant Women in Germany. In Proceedings of the 2017 ACM Conference Companion Publication on Designing Interactive Systems (pp. 144-149). ACM. https://doi.org/10.1145/3064857.3079135

Weibert, A., Mouratidis, M., Khateb, R., Rüller, S., Hosak, M., Potka, S., Aal, K. \& Wulf, V. (2017b). Creating environmental awareness with upcycling making activities: A study of children in Germany and Palestine. In Proceedings of the 2017 Conference on Interaction Design and Children (pp. 286-291). ACM. https://doi.org/10.1145/3078072.3079732

Weibert, A., Randall, D., \& Wulf, V. (2017). Extending Value Sensitive Design to Off-the-Shelf Technology: Lessons Learned from a Local Intercultural Computer Club. Interacting with Computers, 29(5), 715-736. https://doi.org/10.1093/iwc/iwx008

Weibert, A. \& Wulf, V. (2010). "All of a sudden we had this dialogue..." intercultural computer clubs' contribution to sustainable integration. In Proceedings of the 3rd international conference on Intercultural collaboration (pp. 93-102). ACM. https://doi.org/10.1145/1841853.1841868

Weise, F. J., Hauptmeier, H., Stratford, K. J., Hayward, M. W., Aal, K., Heuer, M., Tomeletso, M., Wulf, V., Somers, M. J., \& Stein, A. B. (2019). Lions at the Gates: Trans-disciplinary Design of an Early Warning System to Improve Human-Lion Coexistence. Frontiers in Ecology and Evolution, 6. https://doi.org/10.3389/fevo.2018.00242

Whyte, W. F., Greenwood, D. J., \& Lazes, P. (1991). Participatory action research: Through practice to science in social research. In Participatory action research (pp. 19-55). Sage. https://doi.org/10.4135/9781412985383.n2

Witzel, A. (2000). Das problemzentrierte Interview. Forum Qualitative Social Research, 1(1). Article no. 22.

Wilson, C., McNaney, R., Roper, A., Capel, T., Scheepmaker, L., Brereton, M., Wilson, S., Green, D. G. \& Wallace, J. (2020). Rethinking Notions of 'Giving Voice' in Design. In Extended Abstracts of the 2020 CHI Conference on Human Factors in Computing Systems (pp. 1-8). ACM. https://doi.org/10.1145/3334480.3375171

Winter, R. (2008). Design science research in Europe. European Journal of Information Systems, 17(5), 470-475. https://doi.org/10.1057/ejis.2008.44

Wulf, V., Pipek, V., \& Won, M. (2008). Component-based tailorability: Enabling highly flexible software applications. International Journal of Human-Computer Studies, 66(1), 1-22. https://doi.org/10.1016/j.ijhcs.2007.08.007

Wulf, V., Müller, C., Pipek, V., Randall, D., Rohde, M., \& Stevens, G. (2015). Practice-based computing: Empirically grounded conceptualizations derived from design case studies. In Designing socially embedded technologies in the realworld (pp. 111-150). Springer. https://doi.org/10.1007/978-1-4471-6720-4 7

Wulf, V., Aal, K., Abu Kteish, I., Atam, M., Schubert, K., Rohde, M., Yerousis, George P. \& Randall, D. (2013a). Fighting against the wall: Social media use by political activists in a Palestinian village. In Proceedings of the SIGCHI Conference on Human Factors in Computing Systems (pp. 1979-1988). ACM. https://doi.org/10.1145/2470654.2466262 
Wulf, V., Misaki, K., Atam, M., Randall, D., \& Rohde, M. (2013b). 'On the ground' in Sidi Bouzid: investigating social media use during the Tunisian revolution. In Proceedings of the 2013 conference on Computer supported cooperative work (pp. 1409-1418). ACM. https://doi.org/10.1145/2441776.2441935

Wulf, V., Rohde, M., Pipek, V., \& Stevens, G. (2011). Engaging with practices: design case studies as a research framework in CSCW. In Proceedings of the ACM 2011 conference on Computer supported cooperative work (pp. 505-512). ACM. https://doi.org/10.1145/1958824.1958902

Wulf, V., \& Rohde, M. (1995). Towards an integrated organization and technology development. In Proceedings of the 1st conference on Designing interactive systems: processes, practices, methods, \& techniques (pp. 55-64). ACM. https://doi.org/10.1145/225434.225441

Yerousis, G., Aal, K., von Rekowski, T., Randall, D. W., Rohde, M., \& Wulf, V. (2015). Computer-enabled project spaces: Connecting with Palestinian refugees across camp boundaries. In Proceedings of the 33rd annual ACM conference on human factors in computing systems (pp. 3749-3758). ACM. https://doi.org/10.1145/2702123.2702283

Zegura, E. W., \& Grinter, R. E. (2013). Community building for capacity building: case study of Liberia's iLab. In Proceedings of the Sixth International Conference on Information and Communications Technologies and Development: Notes Volume 2 (pp. 171-174). ACM. https://doi.org/10.1145/2517899.2517936

Zweig, K., Neuser, W., Pipek, V., Rohde, M., \& Scholtes, I. (Eds.). (2014). Socioinformatics - The Social Impact of Interactions between Humans and IT. Springer.

Editorial record: The article has been peer-reviewed. First submission received on 14 September 2021. Revision received on 6 November 2021 and 17 December 2021. Accepted for publication on 20 December 2021. The editors coordinating the peer-

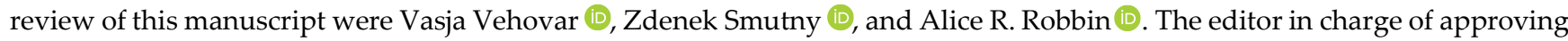
this manuscript for publication was Zdenek Smutny.

Special Issue: Perspectives of Social Informatics.

Acta Informatica Pragensia is published by Prague University of Economics and Business, Czech Republic.

ISSN: $1805-4951$ 